\title{
A New Model for Measuring Customer Utility Trust in Online Auctions
}

\author{
El-Sayed M. El-Kenawy \\ Communications and Electronics \\ Engineering Department \\ Delta Higher Institute for \\ Engineering \& Technology, Talkha \\ 35111, Egypt
}

\author{
Marwa Eid \\ Communications and Electronics \\ Engineering Department \\ Delta Higher Institute for \\ Engineering \& Technology, Talkha \\ 35111, Egypt
}

\author{
Alshimaa H. Ismail \\ Communications and Electronics \\ Engineering Department \\ Delta Higher Institute for \\ Engineering \& Technology, Talkha \\ 35111, Egypt
}

\begin{abstract}
Reports from the US Federal Bureau of investigation have indicated a lot of unethical activities taking place on the internet environments. Despite some technical challenges, ethical related complaints have elicited studies on trust in online commercial transactions like auctioneering. By looking closely on issues that are related to online trust, this study has developed a model that can be used to ascertain trust levels in various websites. The trust issues taken into consideration are Industry Reputation (Ri), Website Reputation (Wi), E-loyalty (Le), Price Premiums (Pp), Social Network (Sn), Value of Good $(\mathrm{Vg})$, Ease of Use (Eu) and Company Satisfactory Transactions (St). In this respect, the level of trust in an auctioneering website has been equated to one's utility. Presumably, if one derives satisfaction from more goods at the company, it is evident that his trust level will be higher. The model has been found to be of good reliability and validity in measuring trust levels in a survey in this study.
\end{abstract}

\section{Keywords}

Trust model Social networks, Online Auctions, Fraud

\section{INTRODUCTION}

Despite the fact that many sales by auctions are now being done online, by millions of internets users around the globe, there have been no literature that offer a precise understanding on how trust in the online auctions can be $[1,2]$ Although online auctioneering has been dynamic in business-tobusiness (B2B) business-to-consumer (B2C) and consumerto-consumer $(\mathrm{C} 2 \mathrm{C})$ models, most literatures have reduced parties involved into two: the seller and the buyer $[3,4]$

According to [5] online auction has been seen to benefit many vendors and buyers because it saves time, reduces the number of suppliers, standardizes the sourcing process, helps the organization to standardize contractual terms and conditions and ensures that both sellers and buyers transact at competitive prices. However, limitations such as possibility of fraud, limited participation, security, long cycle time and monitoring time have seen the participants distrusting some auctioneering websites. Trust has been defined as the general relationship that arises as a result of opinions or held attitudes towards others $[6,7,8]$.

\section{FACTORS AFFECTING TRUST}

Website Reputation: It has been evident that what auction participants think about the Auction Website's performance could be a source of trust or distrust [8]. Industry reputation: Collective information regarding the reputation of various players in a certain auction industry would affect the trust that people accord to a certain website [9].

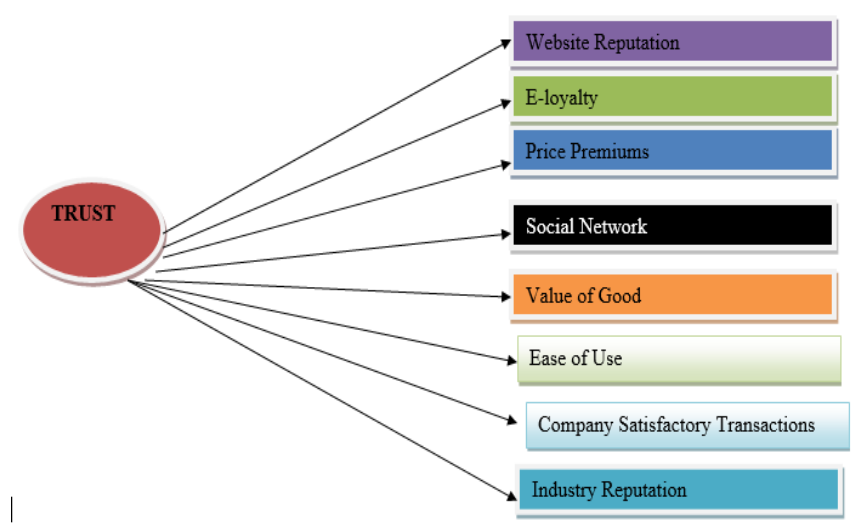

Figur1. The Formal Framework of the Trust Model

E-loyalty: The trust of participating in online auction deals is also determined by a person's loyalty or trust in the general web transactions $[10,11]$.

Price Premiums: Increases of prices of a product from the time a new bid is done will improve a website's rating $[12,13]$.

Ease of use: the level of one's shopping enjoyment as marked by the ease of use will determine the trust a person will have in the online shopping $[14,15]$.

Social networks and reference persons: Participant social networks and reference groups have been said to build the reputation of an auction $[16,17,18]$

Satisfactory transactions: the online auctions. Satisfactory transactions are the main driving forces behind customer trust and loyalty $[19,20]$.

Value of good: The quality of the product, if bidders view a product with higher prices, they would think of a more profitable organization $[21,22,23]$. These factors are shown in Figure 1.

\section{FIGURES/CAPTIONS}

In a survey to experiment the implementation of this model, participants from Microhard's Online Auction were chosen for a discussion about their experience during online auctions with the company. A preliminary online chat with the thirty choices was done to learn if they potentially fitted the needs for the survey such as online auction experience, time spent on the internet, social networks and units of goods bought. Twenty individuals from those contacted took part in the survey by responding to the Company's online questionnaire. The results were as table 1 show. 


\begin{tabular}{|c|c|c|c|c|c|c|c|c|c|c|c|c|c|c|}
\hline 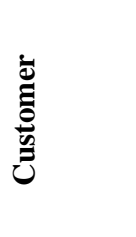 & 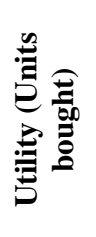 & 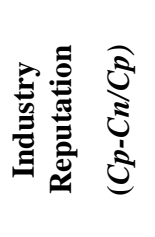 & 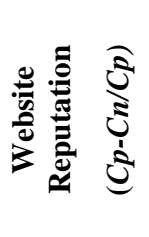 & 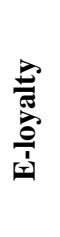 & 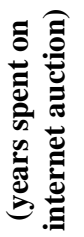 & 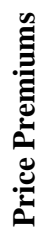 & 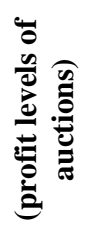 & 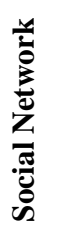 & 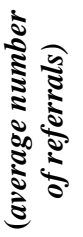 & 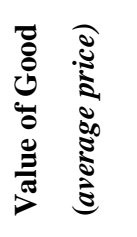 & 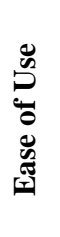 & 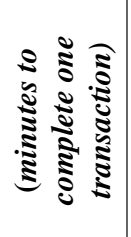 & 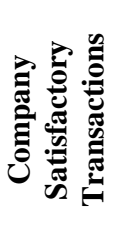 & 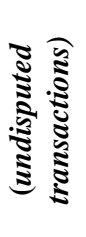 \\
\hline 1 & 100 & 10 & 100 & & 2 & & 300 & & 1 & 1000 & & 40 & 40 & \\
\hline 2 & 120 & 12 & 120 & & 3 & & 330 & & 2 & 1500 & & 35 & 40 & \\
\hline 3 & 95 & 9.5 & 95 & & 2 & & 290 & & 1 & 980 & & 40 & 40 & \\
\hline 4 & 200 & 20 & 210 & & 5 & & 350 & & 5 & 2100 & & 25 & 40 & \\
\hline 5 & 122 & 12 & 120 & & 2.5 & & 300 & & 3 & 1020 & & 33 & 40 & \\
\hline 6 & 150 & 15 & 140 & & 4 & & 400 & & 6 & 1600 & & 30 & 40 & \\
\hline 7 & 100 & 10 & 110 & & 2 & & 300 & & 2 & 1000 & & 39 & 40 & \\
\hline 8 & 80 & 7.5 & 80 & & 1 & & 280 & & 1 & 850 & & 45 & 40 & \\
\hline 9 & 98 & 10 & 100 & & 1 & & 300 & & 1 & 1000 & & 42 & 40 & \\
\hline 10 & 145 & 15 & 145 & & 5 & & 400 & & 5 & 1500 & & 31 & 40 & \\
\hline 11 & 244 & 24.2 & 243.6 & & 8 & & 450 & & 8 & 2400 & & 20 & 40 & \\
\hline 12 & 234 & 20.9 & 239 & & 7.7 & & 435 & & 7 & 2350 & & 20 & 40 & \\
\hline 13 & 216 & 22 & 220 & & 6.7 & & 316 & & 7 & 2170 & & 24 & 40 & \\
\hline 14 & 216 & 21 & 230 & & 7 & & 413 & & 9 & 2380 & & 10 & 40 & \\
\hline 15 & 422 & 40 & 410 & & 11 & & 810 & & 15 & 4000 & & 12 & 40 & \\
\hline 16 & 287 & 28 & 270 & & 9 & & 490 & & 10 & 2920 & & 18 & 40 & \\
\hline 17 & 385 & 38 & 380 & & 10 & & 500 & & 13 & 3700 & & 12 & 40 & \\
\hline 18 & 367 & 37 & 400 & & 10 & & 500 & & 12 & 3590 & & 13 & 40 & \\
\hline 19 & 290 & 28 & 300 & & 12 & & 480 & & 12 & 2860 & & 14 & 40 & \\
\hline 20 & 316 & 30 & 320 & & 11 & & 490 & & 13 & 3090 & & 13 & 40 & \\
\hline Averages & 209.4 & 20.5 & 211.6 & & 6 & & 406.7 & & 6.65 & 2100.5 & & 25.8 & 40 & \\
\hline
\end{tabular}

From the results shown in table 1, the model for the nominal utility is as follows:

$U=-25.707+5.379 R i+0.245 \mathrm{Wi}+0.975 \mathrm{Le}+0.053 \mathrm{Pp}+$ $0.676 \mathrm{Sn}+0.016 \mathrm{Vg}+0.295 \mathrm{Eu}+0 \mathrm{St}+0 \varepsilon_{\mathrm{q}}$

However, for one to get the real utility, $\hat{\mathrm{U}}$, he must adjust the nominal utility, $\mathrm{U}$, with the enduring trustworthiness, $\theta$. Suppose that the exogenous $\theta=\mathrm{V} 2$ the enduring real utility $\hat{U}$.

\section{Consideration of the Results of the Above Experiment}

\section{Individual customer Utility or trust in the Company}

The Nominal utility for the first customer;

$U=-25.707+5.379(10)+0.245(100)+0.975(2)+0.053$ $(300)+0.676(1)+0.016(1000)+0.295(40)+0(40)=98.909$

Suppose the enduring vector of company trustworthiness V2= 0.64 Or 0.82 , the real utility, and thus the real level of customer's trust will be:

$0.64(98.909)=63.30176$ units of goods

His utility or trust in the Company's goods will be maximized when

$\delta 2 \hat{U} / \delta V 2=0$

Thus 2(98.909) $=197.818$ units

Average customer utility in the Company

$U=-25.707+5.379(20.5)+0.245(211.6)+0.975(6)+0.053$ $(406.7)+0.676(6.65)+0.016(2100.5)+0.295(25.8)+0(40)$ $=209.524$

Since the vector of company trustworthiness V2 $=0.64$ 0r 0.82 the real average utility will be

$0.64(209.524)=134.09536$

However, it will be maximized at $\delta 2 \hat{\mathrm{U}} / \delta \mathrm{V} 2=0$

$\hat{U}=V 2(209.524)$

$\delta 2 \hat{U} / \delta V 2=2(209.524)=419.048$ units

Thus, the company average utility or trust will be maximized when its average customer utility reaches 419.048 units of goods sold. As shown in figure 2 


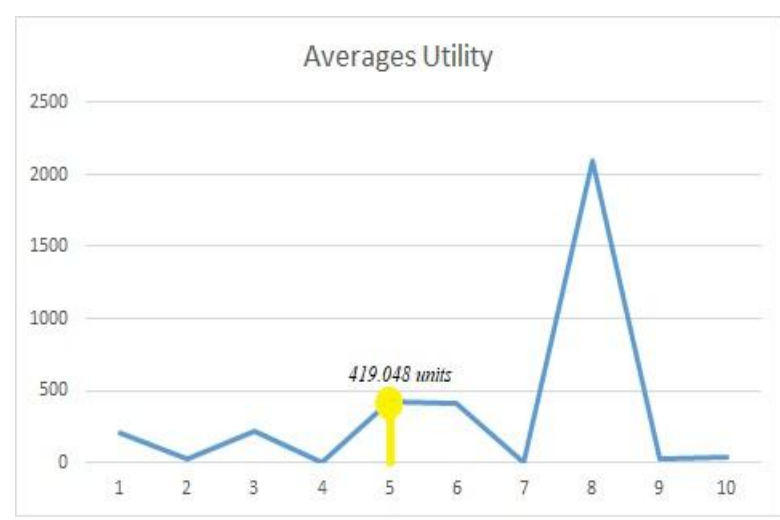

Figur2. Average Customer Utility Units

\section{CONCLUSIONS}

Online auction has become particularly much vulnerable to individuals and companies due to unethical behaviors such as fraud. Together with technical problems, online auctioneering companies have to ensure that they eliminate them, to enhance trust in bidders. The study has also shown that the whole industry bidding environment is also likely to affect bidding tendencies in many participants. This puts pressure on the auctioneering firm to point out fraudulent companies and individuals to protect innocent bidders. However, individual attitudes, due to the number of years spent in bidding could also reveal the level of confidence one will have in online auction. However, the online auction and prices of goods under consideration will also impact heavily on customer utility and trust. Noting that the study has had several limitations, future models should incorporate them. Study items that are of rational nature, could be quantified using validly recognized scales in Social Sciences. The studies would also ensure that only real bidders, from different companies and industries are allowed to take the questionnaires. Further, the number of bidders and companies should be larger for more precise and universally accepted results. Finally, future models that consider units of several products are also welcome.

\section{REFERENCES}

[1] El-Kenawy, E. S. M. T., El-Desoky, A. I., \& Sarhan, A. M. (2014). A bidder strategy system for online auctions trust measurement. International Journal of Strategic Information Technology and Applications (IJSITA), 5(3), 37-47.

[2] Hassib, E. M., El-Desouky, A. I., Labib, L. M., \& Elkenawy, E. S. M. WOA+ BRNN: An imbalanced big data classification framework using Whale optimization and deep neural network. Soft Computing, 1-20.

[3] M. A. Mohamed, M. E. A. Abou-Elsoud and M. M. Eid, "An efficient algorithm in extracting human iris Morphological features," 2009 International Conference on Networking and Media Convergence, Cairo, 2009, pp. 146-150.

[4] M. A. Mohamed, M. A. Abou-El-Soud and M. M. Eid, "Automated algorithm for iris detection and code generation," 2009 International Conference on Computer Engineering \& Systems, Cairo, 2009, pp. 475-481.

[5] El-kenawy, E. S. M., El-Desoky, A. I., \& Al-rahamawy, M. F. (2012). Distributing Graphic Rendering using Grid Computing with Load Balancing. International Journal of Computer Applications, 975, 888.
[6] El-kenawy, E. S. M. T. (2019). A Machine Learning Model for Hemoglobin Estimation and Anemia Classification. International Journal of Computer Science and Information Security (IJCSIS), 17(2).

[7] M. A. Mohamed, M. E. Abou-Elsoud and M. M. Eid, "Automated face recogntion system: Multi-input databases," The 2011 International Conference on Computer Engineering \& Systems, Cairo, 2011, pp. 273280.

[8] Hikal, N. A., \& Eid, M. M. (2018). A new approach for palmprint image encryption based on hybrid chaotic maps. Journal of King Saud University-Computer and Information Sciences.

[9] Hassib, E. M., El-Desouky, A. I., El-kenawy, E. S. M., \& Elghamrawy, S. (2019). An Imbalanced Big Data Mining Framework for Improving Optimization Algorithms Performance. IEEE Access.

[10] El-Knawy, E. S. M. T., \& El-Desoky, A. I. (2016). TRUST MEASUREMENT FOR ONLINE AUCTIONS: PROPOSAL OF NEW MODEL. INTERNATIONAL JOURNAL OF INNOVATIVE COMPUTING INFORMATION AND CONTROL, 12(2), 385-394.

[11] El-sayed, M., El-Desoky, A. I., \& Sarhan, A. M. (2014). A bidder behavior learning intelligent system for trust measurement. International Journal of Computer Applications, 89(8).

[12] Reham Arnous, El-Sayed Towfek M El-kenawy and M Saber. A Proposed Routing Protocol for Mobile Ad Hoc Networks. International Journal of Computer Applications 178(41):26-30, August 2019.

[13] El-Sayed Towfek M El-kenawy. Trust Model for Dependable File Exchange in Cloud Computing. International Journal of Computer Applications 180(49):22-27, June 2018.

[14] Mohamed, M. A., Abou-El-Soud, M. E. A., \& Eid, M. M. (2014). Iris detection and normalization in image domain based on morphological features. International Journal of Computer Science Issues (IJCSI), 11(1), 51.

[15] Eid, M. M., Mohamed, M. A., \& Abou-El-Soud, M. A. (2015). Development of Iris Security System Using Adaptive Quality-Based Template Fusion. In Intelligent Data Analysis and Applications (pp. 265-278). Springer, Cham.

[16] El-Sayed Towfek M El-kenawy, M Saber and Reham Arnous. An Integrated Framework to Ensure Information Security Over the Internet. International Journal of Computer Applications 178(29):13-15, July 2019

[17] El-kenawy, E. S. M. T. (2018). Solar Radiation Machine Learning Production Depend on Training Neural Networks with Ant Colony Optimization Algorithms. IJARCCE, 7(5).DOI10.17148/IJARCCE.20 18.751 .

[18] H. Hassan, A. I. El-Desouky, A. Ibrahim, E. M. Elkenawy and R. Arnous, (2020) "Enhanced QoS-based Model for Trust Assessment in Cloud Computing Environment," in IEEE Access. doi 10.1109/ACCESS.2020.2978452

[19] Noshy, M., Ibrahim, A., \& Ali, H. A. (2018). Optimization of live virtual machine migration in cloud 
computing: A survey and future directions. Journal of Network

[20] Noshy, M., Ibrahim, A., \& Ali, H. A. (2018). Optimization of live virtual machine migration in cloud computing: A survey and future directions. Journal of Network and Computer Applications, 110, 1-10.

[21] Ibrahim, A., Tharwat, A., Gaber, T., \& Hassanien, A. E. (2018). Optimized superpixel and AdaBoost classifier for human thermal face recognition. Signal, Image and Video Processing, 12(4), 711-719.

[22] Elhosuieny, A., Salem, M., Thabet, A., \& Ibrahim, A. (2019). ADOMC-NPR Automatic Decision-Making
Offloading Framework for Mobile Computation Using Nonlinear Polynomial Regression Model. International Journal of Web Services Research (IJWSR), 16(4), 5373.

[23] El-Gendy, E., Ibrahim, A. F., Saraya, S. F., \& Areed, F. F. (2013). A sliding mode controller for a three-phase induction motor. International Journal of Computer Applications, 64(11).[23] Ibrahim, A., Mohammed, S., \& Ali, H. A. (2018, February). Breast cancer detection and classification using thermography: a review. In International Conference on Advanced Machine Learning Technologies and Applications (pp. 496-505). Springer, Cham. 